\title{
Falciparum Malaria
}

National Cancer Institute

\section{Source}

National Cancer Institute. Falciparum Malaria. NCI Thesaurus. Code C34798.

Malaria resulting from infection by Plasmodium falciparum. 